\title{
Noradrenergic Action in Prefrontal Cortex in the Late Stage of Memory Consolidation
}

\author{
Sophie Tronel, ${ }^{1}$ Matthijs G.P. Feenstra, ${ }^{2}$ and Susan J. Sara ${ }^{1,3}$ \\ ${ }^{1}$ Neuromodulation and Memory Processes, Unité Mixte de Recherche 7102, Centre National de la Recherche \\ Scientifique, Université Pierre et Marie Curie, Paris 75005, France; ${ }^{2}$ Netherlands Institute for Brain Research, \\ 1105 AZ Amsterdam, The Netherlands
}

\begin{abstract}
These experiments investigated the role of the noradrenergic system in the late stage of memory consolidation and in particular its action at $\beta$ receptors in the prelimbic region (PL) of the prefrontal cortex in the hours after training. Rats were trained in a rapidly acquired, appetitively motivated foraging task based on olfactory discrimination. They were injected with a $\beta$ adrenergic receptor antagonist into the PL 5 min or $2 \mathrm{~h}$ after training and tested $48 \mathrm{~h}$ later. Rats injected at $2 \mathrm{~h}$ showed amnesia, whereas those injected at $5 \mathrm{~min}$ had good retention, equivalent to saline-injected controls. Monitoring extracellular noradrenaline efflux in PL by in vivo microdialysis during the first hours after training revealed a significant increase shortly after training, with a rapid return to baseline, and then another increase around the 2-h posttraining time window. Pseudo-trained rats showed a smaller early efflux and did not show the second wave of efflux at $2 \mathrm{~h}$. These results confirm earlier pharmacological and immunohistochemical studies suggesting a delayed role of noradrenaline in a late phase of long-term memory consolidation and the engagement of the PL during these consolidation processes.
\end{abstract}

There is a growing body of evidence from behavioral studies suggesting that the prelimbic (PL) and infralimbic regions of rat frontal cortex are involved in executive functions requiring attentional shift and behavioral flexibility, and in working memory (Kesner 1989; Birrell and Brown 2000; deBruin et al. 2000; Jodo et al. 2000; Mulder et al. 2000). Recent experiments in our laboratory suggest that this region is not only involved in these higher 'executive functions,' but is also important in the posttraining consolidation of memory of a simple odor-reward association. The task used is a three-way discrimination among odors, one of which is associated with a palatable reward. Taking advantage of the spontaneous foraging behavior of the rat, reliable learning is achieved in only three trials massed over a few minutes. The memory endures for at least 1 wk without showing any decline. Immunoreactivity to c-fos antibody has been used as a marker for neuronal activation after training and after a control condition in which rats were exposed to all of the elements of the training but not the odor-reward association. Not surprisingly, many regions were equally activated by both the control and trained conditions. Nevertheless, there were three regions which stood out as differentially activated specifically by the associative training. These were the basolateral amygdala, the ventral orbital cortex, and the PL of the prefrontal cortex (Tronel and Sara 2002). These experiments show that these regions are activated as a result of the training, but they do not prove that they are necessary to the learning or memory process. Subsequent experiments added further support for this notion; injections of the NMDA receptor antagonist APV into the PL immediately after training induced a robust and enduring amnesia expressed when the rats were tested $48 \mathrm{~h}$ later (Tronel and Sara 2003).

Studies of neuromodulatory influences in prefrontal cortex have focused for the most part on dopamine effects, but noradrenergic neurons of the LocusCoeruleus project to all regions of the frontal cortex (Morrison et al. 1978; Sakaguchi and Naka-

\section{${ }^{3}$ Corresponding author.}

E-MAIL sjsara@ccr.jussieu.fr; FAX 33-1-4427-3252.

Article published online ahead of print. Article and publication date are at http://www.learnmem.org/cgi/doi/10.1101/lm.74504. mura 1987), and the literature documenting noradrenergic influences on neuronal and cognitive function in these regions is considerable (for review, see Arnsten 1997). Our previous investigations of the role of noradrenaline (NE) in memory consolidation suggested that it is involved in a late phase of consolidation, rather than immediately after training (Roullet and Sara 1998; Sara et al. 1999). Intracerebroventricular (icv) injections of the $\beta$-receptor antagonist timolol induced amnesia in the same olfactory discrimination task, when it was injected $2 \mathrm{~h}$ after training, but not immediately or $5 \mathrm{~h}$ later. The present series of experiments further explored the involvement of the PL in memory formation of the odor-reward association by blocking $\beta$-adrenergic receptors in the region after training. Two posttraining time points were examined, and we again found an amnesic effect when the timolol treatment was delayed, but not when it was administered immediately after the training.

The present experiments corroborate this delayed involvement of the NE system in memory consolidation in the PL. Microdialysis was used to monitor extracellular NE in the hours following the end of the learning of the odor-reward association, to determine whether there was a delayed efflux in this region, corresponding to the narrow time window of efficacy of timolol treatment.

\section{RESULTS}

\section{Experiment 1}

\section{Task Acquisition}

There was a significant decrease in latency to find the correct sponge and make the nose-poke response over trials. The rats sniffed the edges of the sponges and rarely made a nose-poke error by the third trial.

\section{Retention}

Latency

Timolol injections into the prelimbic cortex $2 \mathrm{~h}$ after the end of the training produced amnesia when rats were tested $48 \mathrm{~h}$ later, 
whereas there was no effect when the injection was made immediately after training (Fig. 1). There was a significant effect of training-treatment delay $(\mathrm{F}(1,49)=5.04 ; P=0.02)$, a significant effect of repetition $(\mathrm{F}(3,147)=14.98 ; P<0.0001)$, a significant interaction of drug $\times$ injection time $(\mathrm{F}(1,49)=7.67 ; P=0.008)$, and most important, there was a highly significant drug $\times$ injection time $\times$ repetition interaction $(\mathrm{F}(3,147)=6.01 ; P=0.0007)$. Planned orthogonal comparisons revealed a significant difference between control and timolol- $2 \mathrm{~h}$ groups at the first test trial $(P<0.01)$. The timolol-2 h group was significantly different from the timolol-5 min group as well $(P<0.01)$. The performances at the first test trial for the timolol- $2 \mathrm{~h}$ group were significantly different from both the last acquisition trial $(P<0.01)$ and the second test trial $(P<0.01)$, showing an amnesic effect and the ability to relearn the task, respectively.

\section{Errors}

A similar pattern of results was seen when errors were considered as the performance measure (Fig. 2). There was a significant effect of repetition $(\mathrm{F}(3,147)=15.82 ; P<0.0001)$, a significant interaction of drug $\times$ repetition $(\mathrm{F}(3,147)=6.5 ; P=0.0003)$, and a significant drug $\times$ injection time $\times$ repetition interaction $(\mathrm{F}(3,147)=3.68 ; P=0.01)$. Planned orthogonal comparisons confirmed that the timolol- $2 \mathrm{~h}$ group made significantly more errors at the first test trial than the timolol-5 min and control groups $(P<0.01)$.

\section{Experiment 2}

If $\beta$-receptor blockade is particularly effective in producing amnesia at this narrow time window, $2 \mathrm{~h}$ after learning, one might expect an increase in release of NE at this time. Extracellular NE was monitored continuously for over $2 \mathrm{~h}$ after odor-reward training to determine whether there was a temporal dynamic of NE release corresponding to the time window of opportunity to induce amnesia by $\beta$-receptor blockade observed in the previous experiment.

\section{Behavior}

There was a significant decrease in latency to make the correct response over trials [Fig. 3; significant effect of the repetition

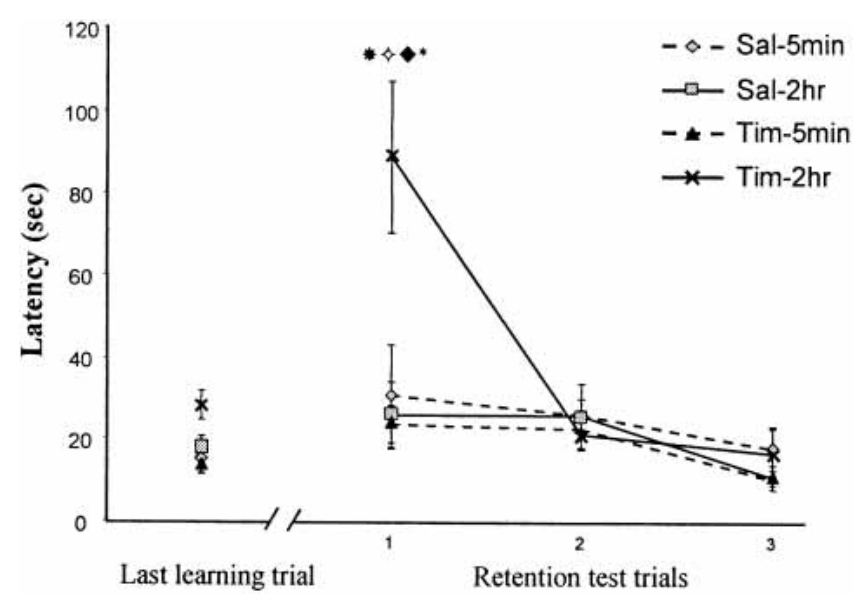

Figure 1 Timolol injections in the prelimbic cortex. Latency to make the correct response over the last training trial and the retention trials. Groups were treated $5 \mathrm{~min}$ or $2 \mathrm{~h}$ after training with timolol or saline. The retention was $48 \mathrm{~h}$ later. The Tim- $2 \mathrm{~h}$ group is significantly different from the sal- $2 \mathrm{~h}\left({ }^{*} P<0.01\right)$ and from the Tim-5 min group $(\diamond P<0.01)$ at the retention test. The performances at the first test trial for the Tim- $2 \mathrm{~h}$ group were significantly different from both the last acquisition trial $(\diamond P<0.01)$ and the second test trial $\left({ }^{*} P<0.01\right)$, showing an amnesic effect and the ability to relearn the task, respectively.

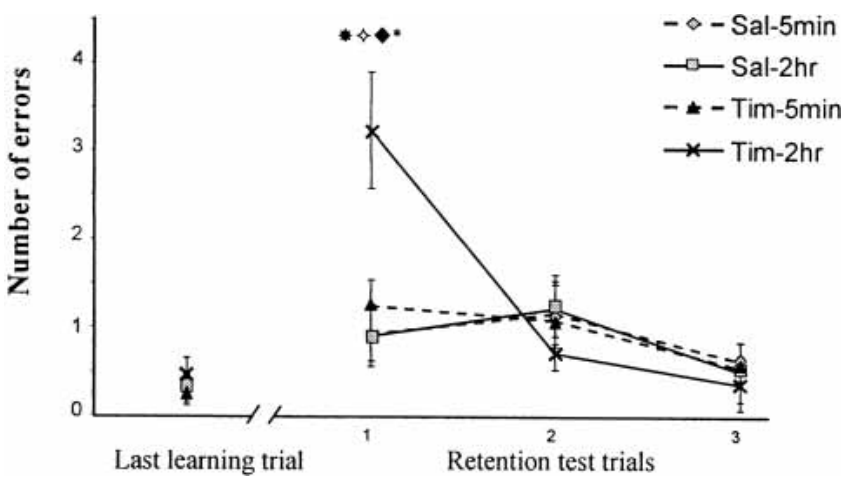

Figure 2 Timolol injections in the prelimbic cortex. Number of errors before making the correct response over the last training trial and the retention trials. Groups were treated $5 \mathrm{~min}$ or $2 \mathrm{~h}$ after training with timolol or saline solution. The retention was $48 \mathrm{~h}$ later. The Tim- $2 \mathrm{~h}$ group is significantly different from the sal- $2 \mathrm{~h}\left({ }^{*} P<0.01\right)$ and from the Tim-5 min group $(\diamond P<0.01)$ at the retention test. The performances at the first test trial for the Tim- $2 \mathrm{~h}$ group were significantly different from both the last acquisition trial $(\diamond P<0.01)$ and the second test trial $\left({ }^{*} P<0.01\right)$, showing an amnesic effect and the ability to relearn the task, respectively.

$(\mathrm{F}(5,20)=14.46 ; P<0.0001))]$. Planned comparisons revealed a significant difference between the first acquisition trial and the second and third trials $(P<0.01)$, and between the second acquisition trial and the third one $(P<0.01)$, and most important, there was no difference between the third acquisition trial and the first retention trial. The performances at the retention test showed that the association was remembered $6 \mathrm{~d}$ after the initial training. The same pattern of results was seen when errors were considered as the performance measures.

\section{Microdialysis}

The mean baseline values of the last three measurements taken before training were $3.1 \pm 0.7 \mathrm{pg} / 50 \mu \mathrm{L}$ for the to-be-trained group and $3.0 \pm 0.6 \mathrm{pg} / 50 \mu \mathrm{L}$ for the yoked control group.

The means of the normalized efflux values (see Materials and Methods), in trained and pseudotrained rats for each time window are shown in Figure 4. There was a significant effect of time of measurement $(F(7,56)=3.64 ; P=0.002)$ and a significant group $\times$ time of measurement interaction $(\mathrm{F}(7,56)=2.53$; $P=0.02$ ). Planned orthogonal comparisons using the Fischer test revealed a significant between-group difference for samples 1 and 7, taken $32 \mathrm{~min}$ and $128 \mathrm{~min}$ after the end of the training, respectively $(P<0.05)$. For the trained group, the level of NE was significantly higher at $128 \mathrm{~min}$ compared to the previous sample taken 16 min before $(P<0.05)$. There were no differences between groups at any other time points, as seen in Figure 4.

\section{DISCUSSION}

The effective site of action of the timolol treatment in the prelimbic region of the prefrontal cortex confirms the importance of this anatomical locus in postacquisition memory consolidation for the olfactory discrimination task. This was initially indicated by the marked increase in c-fos immunostaining, specifically in this region in trained rats, compared to yoked pseudotrained controls (Tronel and Sara 2002). Interestingly, electrophysiological recordings from neurons in PL during the acquisition of this same odor discrimination task revealed a population of neurons that fire vigorously during the intertrial intervals with increasing frequency until the posttrial interval immediately preceding the expression of asymptotic performance. (Kublik and Sara 2002). This posttrial bursting activity could account for the increase in c-fos seen 90 min later when the rats were sacrificed. 


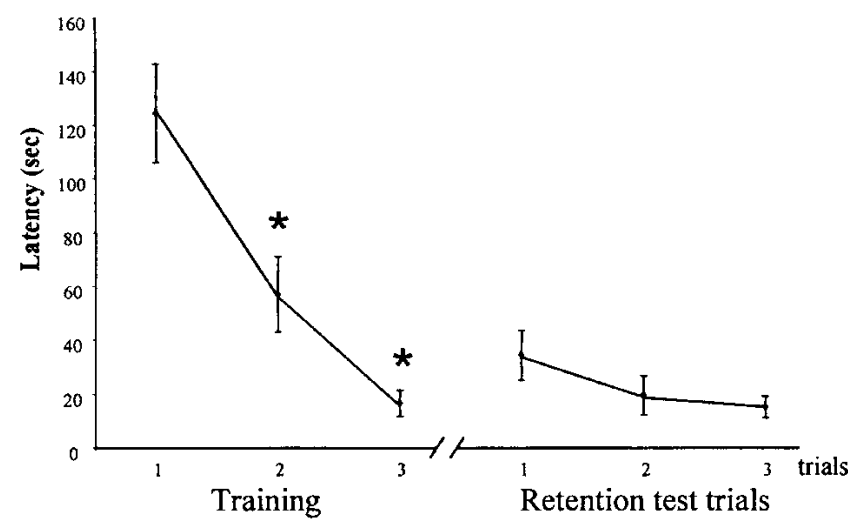

Figure 3 Latency to make the nose-poke response to the target odor during the three acquisition trials and the three retention trials, $6 \mathrm{~d}$ later. There was a significant decrease in the time to make the correct response $\left(^{*}\right)$ over the three acquisition trials and no difference between the last acquisition trial and the first retention trial.

Other studies from our laboratory suggested that NMDA receptors in the PL region are important in the early stages of memory consolidation. Amnesia is obtained after injection of the NMDA receptor antagonist APV into the ventricles or directly into the PL, but not in hippocampus, immediately after training (Tronel and Sara 2003). Using a quite different approach, Quirk's group provided evidence for the medial frontal cortex as an important site of consolidation of memory for extinction of conditioned fear (Quirk et al. 2000; Milad and Quirk 2002).

It should be noted that, although the memory deficit was robust and reliable on the two retention tests, relearning occurred rapidly after reinforcement was reintroduced on trial 2. By trials 3 and 4, as shown at the right of Figures 1 and 2 as relearning, there was no longer any deficit. This phenomenon of rapid relearning was observed in our previous experiments using the same behavioral paradigm, after injection of timolol intracerebroventricularly (Sara et al. 1999), and after injection of an NMDA receptor antagonist into the prelimbic cortex (Tronel and Sara 2003). Thus we can be sure that the drug treatment does not have proactive motivational or perceptive effects that would interfere with performance of the task.

The observation of a role of the noradrenergic system in a later stage of memory consolidation is now surprisingly consistent. The 2-h time window that was seen with icv injections in previous experiments using the same behavioral task (Sara et al. 1999) was replicated here with the in situ cortical injections. We have also reported a delayed effect of icv-injected timolol after reactivation of a spatial memory. In those experiments, amnesia was obtained 48 $\mathrm{h}$ later, when the injection had been made $1 \mathrm{~h}$, but not $5 \mathrm{~min}, 30 \mathrm{~min}$, or $5 \mathrm{~h}$ after the single, rewarded reactivation trial (Roullet and Sara 1998). Thus the phenomenon of a narrow time window of efficacy of the $\beta$-antagonist treatment is consistent across tasks (olfactory and spatial discrimination) and across paradigms (consolidation and reactivation-reconsolidation), although the timing appears to be a bit different in the two series of experiments.

The small but significant increase of efflux of NE in PL at $2 \mathrm{~h}$ after training corroborates the conclusion from the pharmacological ex- periments that NE has a delayed role in consolidation at this precise time window after learning. This is in contrast to what occurs shortly after training. Injection of timolol $5 \mathrm{~min}$ after the last training trial was ineffective in inducing amnesia in these experiments and in our previous work, and yet there was a significantly greater efflux of NE shortly after training in control rats compared to that of pseudotrained controls, as seen in Figure 3 . This suggests that long-term memory formation is not dependent on activation of the NE system during or immediately after training. Nevertheless, its functional role in short-term memory processes has been suggested by the work of Arnsten (1997).

Noradrenaline has complex effects in the frontal cortex. Stimulation of the locus coeruleus (LC) in anesthetized rats inhibits spontaneous activity and at the same time facilitates evoked responses in the frontal cortex (Mantz et al. 1989). More recent in vitro studies show that NE has a complex effect on GABAergic interneurons in this region (Kawaguchi and Shindou 1998). At a cognitive level, there are many studies in primates, showing that $\alpha 2$ agonists in the frontal cortex facilitate performance in memory tasks (Arnsten 1997). The present experiments suggest that $\mathrm{NE}$ action in this region is not limited to immediate or short-term effects, but is involved in processing of information for long-term storage hours after the initial learning experience, via action at $\beta$-receptors.

A consensus is growing that the cAMP-PKA signaling system is involved in the late protein synthesis-dependent phase of both long-term memory and long-term potentiation (LTP). For example, the $\beta$-receptor agonist isoproteronol, paired with weak ineffective tetanus, can induce a long-lasting LTP (L-LTP; Huang and Kandel 1996). In freely moving rats, reward or punishment administered up to $1 \mathrm{~h}$ after tetanus can prolong a weak LTP to a robust L-LTP (Seidenbecher et al. 1997). This phenomenon is blocked by the $\beta$-antagonist propranolol, and thus is presumably mediated through the release of NE during reinforcement (Bouret and Sara 2004)

The role of the cAMP response element-binding (CREB) protein in the consolidation of L-LTP and LTM is well documented, mostly from investigations using targeted mutant mice. Many of

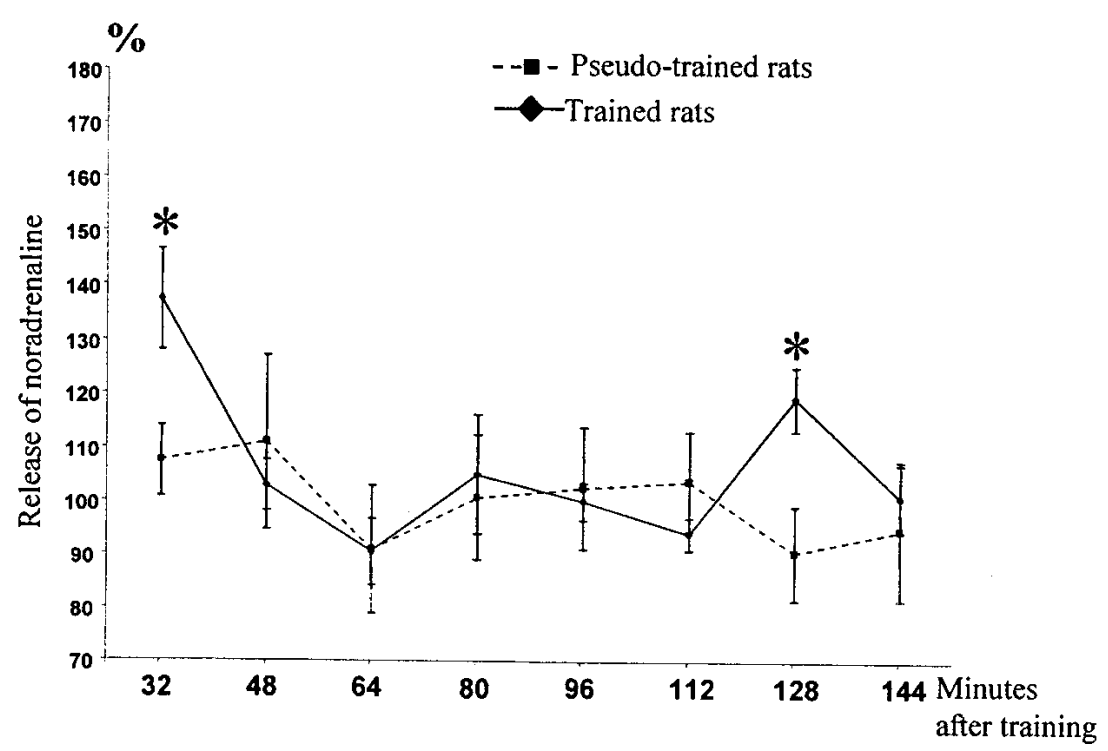

Figure 4 Extracellular NE in the prelimbic cortex in trained and pseudotrained groups (mean percentage of basal level). *: significant difference between the trained and the pseudotrained group and between the 112-min and 128-min time points in the trained group $(P<0.01)$. Note the difference after training, the return to baseline for both groups, and the significant increase in efflux in trained rats at 128 min after training. 
these studies have shown that such mice can learn and remember normally for a few hours, but have deficient LTM (e.g., Bourtchuladze et al. 1994). Several investigators reported a delayed phosphorylation of CREB 2-3 h after LTP induction (Schulz et al. 1999) or learning (Stanciu et al. 2001). This should act as the 'molecular switch' for converting short-term memory to LTM, as suggested by Yin and Tully (1996). It is tempting to propose that delayed activation of the NE system and perhaps other neuromodulatory systems associated with reinforcement and attention, and linked to the cAMP-pCREB pathway, initiate or promote this second stage of memory consolidation. Support for this notion comes from recent results in our laboratory indicating that pCREB-dependent immediate early gene expression in the prelimbic cortex induced by odor discrimination learning can be significantly attenuated if the rats are injected with a $\beta$-antagonist, into the prelimbic cortex, $2 \mathrm{~h}$ after training (Tronel et al. 2003).

In summary, the present results confirm the participation of the prelimbic region of the prefrontal cortex in a prolonged consolidation phase of memory of a simple odor-reward association. Interestingly, Fuster has deduced from highly sophisticated cognitive tasks in monkeys that neurons of the prefrontal cortex 'belong to long-term networks associating two sensory modalities as a result of learning' (Fuster 2003, p.129). Recent electrophysiological recordings from prelimbic neurons in the rat learning this odor-reward association suggest that this is true in the rat as well (Bouret and Sara 2004). The present results, showing the dependence of LTM formation for odor-food association on this prefrontal region, corroborate this view and emphasize that the $\beta$-receptors in this region play a permissive role in the late phase of memory formation in this region. The question remains concerning the physiological mechanism promoting the NE release 2 $\mathrm{h}$ downstream from the initial learning experience.

\section{MATERIALS AND METHODS}

\section{Experiment 1}

Fifty-three male Sprague-Dawley rats (IFFA-Credo; 200-220 g) were used in this experiment. They were housed in pairs in wire mesh cages $(35 \times 20 \times 18 \mathrm{~cm})$ in a temperature- and light-controlled vivarium, maintained on a 12-h light-dark cycle, (light on $8 \mathrm{am})$. All experiments were carried out during the light cycle. All rats were weighed and handled daily from the day of their arrival in the laboratory. There was free access to food and water except during the pretraining, training, and test days, when food was restricted to $15 \mathrm{~g} / \mathrm{rat} / \mathrm{d}$ to maintain body weight at $~ 90 \%$ of freely feeding weight. All experimental procedures were carried out under regulations of the European Union (Guideline 86/609/EEC).

\section{Surgery}

One week after arrival in the laboratory, rats were anesthetized with pentobarbital $(60 \mathrm{mg} / \mathrm{kg})$, restrained in a stereotaxic apparatus, and implanted bilaterally with 26-gauge stainless steel cannulas. Holes were drilled over the prelimbic cortex, and cannulas were positioned $3.2 \mathrm{~mm}$ anterior to bregma; $\pm 0.6 \mathrm{~mm}$ lateral to the midline; ventral, $3 \mathrm{~mm}$ below the surface of the skull, according to the Paxinos and Watson (1986) atlas, and secured in place with three skull screws attached with dental cement. A thin stainless-steel wire was placed inside each cannula to prevent blockage. Animals were allowed $10 \mathrm{~d}$ to recuperate before being subjected to experimental manipulation.

\section{Pharmacological Treatment}

Injections were made by removing the wire and inserting a 33-G stainless steel tube, which extended 1 millimeter below the edge of the cannula. The tube was attached to a catheter and a micro- syringe. The injection volumes were $1 \mu \mathrm{L}$ per side and were delivered over a period of $1 \mathrm{~min}$ while the rat was held gently in the hand of the experimenter, with minimal stress. The injectors were left in position to minimize dragging of the injected liquid along the injection tract. Control rats were injected with sterile saline and the experimental group with timolol at a concentration of $5 \mu \mathrm{g} / \mu \mathrm{L}$.

\section{Apparatus}

The training apparatus and behavioral procedure are described in detail elsewhere (Tronel and Sara 2002). Three glass slide-holders $(6 \times 7 \times 2 \mathrm{~cm})$ containing sponges with a $2-\mathrm{cm}$ diam. hole cut into the center were placed in the corners of a square box made of heavy opaque plastic $(60 \times 60 \times 40 \mathrm{~cm})$. The food reinforcement was placed at the bottom of the hole in the sponge so the rat had to poke its snout into the hole (nose-poke) to obtain the reward: chocolate rice crispy breakfast cereal (Chocopops, Kel$\operatorname{logg}$ 's, France). On the first trial, four Chocopops were also placed on the corners of that sponge impregnated with the target odor, as well as in the hole. The sponges with the nontarget odors did not contain food. The position of each odor within the box was changed for each trial according to a previously determined protocol. The actual set of sponges was changed between trials as well, to preclude any identification based on visual cues. Sponges were impregnated with an odor by placing $15 \mu \mathrm{L}$ of essence on each corner. Odors used were almond, mint, and lemon; previous experiments showed that rats did not show any particular preference or aversion to any of these odors at this concentration.

A video camera was fixed above the apparatus, and the rat was observed on a video monitor in the same room. The session was recorded on video tape for further analysis offline.

\section{Experimental Design and Behavioral Procedures}

Rats were handled and weighed daily during the recovery period. The experiment began with $2 \mathrm{~d}$ of pretraining to familiarize rats with the reinforcement and the experimental box. On the first day, each rat was given free access to the reward for $20 \mathrm{~min}$ in a neutral cage; on the second day, for $10 \mathrm{~min}$ in the same neutral cage, and then the rat was placed in the experimental box without the sponges for 10 min.

Training was carried out the next day in a single three-trial session. Cage mates were kept in the experimental room in a holding cage, and one rat was introduced into the behavioral apparatus, in the corner without a sponge, head toward the wall. There was a 5-min time limit for the rat to find and consume the reinforcement. Intertrial intervals were $2-5 \mathrm{~min}$. The spatial configuration of the sponges was changed between trials, and the reinforcement was always associated with the same odor. Latency before a correct response (nose-poke into the reinforced sponge) and number of errors (nose-poke into incorrect sponges or sniffing the target odor not followed by a nose-poke) were noted.

Animals were assigned to treatment groups according to their performance during training, taking into account response latencies; only rats making no errors at the end of training were included. Rats were injected with the vehicle solution, $5 \mathrm{~min}$ $(\mathrm{n}=13)$ or $2 \mathrm{~h}(\mathrm{n}=10)$ or with timolol, $5 \min (\mathrm{n}=13)$ or $2 \mathrm{~h}$ $(\mathrm{n}=17)$ after training. The injections were made in a quiet room, adjacent to the experimental room.

\section{Retention Test}

Forty-eight hours after training, rats were tested for retention and relearning ability using the same procedure as during training, except that the first test trial was not reinforced and there were a total of three trials. Latency and nose-poke values were scored by an experimenter who was blind to the treatment groups.

After the test, rats were anesthetized with an overdose of Pentobarbital and injected with methylene blue. Brains were removed, frozen, and cut to check the placement of cannulas. All rats had correctly placed cannulas, and the methylene blue was seen in an area restricted to the ventral medial frontal cortex. 


\section{Data Analysis}

Latency to nose-poke and number of errors were taken as the performance measures. Acquisition scores for the entire data set, in terms of latencies and number of errors, were submitted to an analysis of variance for repeated measures (ANOVA).

The retention test data were submitted to a $2 \times 2 \times 4$ ANOVA with repeated measures (last training trial and the three retention trials). The two independent measure factors were drug treatment (saline or timolol) and training-treatment delay (5 min or $2 \mathrm{~h}$ ). ANOVA was complemented by planned comparisons using Fisher's least significant differences (LSD) test.

\section{Experiment 2}

\section{Animals}

Ten male Sprague Dawley rats (Harlan; 200-220 g) were used in this experiment. They were housed in groups of four in macrolon cages $55 \times 33 \times 20 \mathrm{~cm}$ in a temperature- and light-controlled vivarium maintained on a 12-h light-dark cycle (lights on $7 \mathrm{am}$ ). All experiments were carried out during the light cycle. Rats were weighed and handled daily from the day of their arrival in the laboratory. There was free access to food and water except during the pretraining, training, and test period, when food was restricted to $15 \mathrm{~g} / \mathrm{rat} / \mathrm{d}$ to maintain body weight at $~ 90 \%$ of freely feeding weight. Experiments were approved by the Animal Experimentation Committee of the Royal Netherlands Academy of Arts and Sciences and were carried out in agreement with Dutch laws (Wet op Dierproeven 1996) and regulation of the European Union ( Guideline 86/609/EEC).

\section{Surgical Procedures}

On the day of surgery, rats received an intraperitoneal injection of ketamine $(50 \mathrm{mg} / \mathrm{kg})$ and xylazine $(3 \mathrm{mg} / \mathrm{kg})$, followed by an intraventricular infusion with $14 \mathrm{mg} / \mathrm{kg} / \mathrm{h}$ ketamine. Rats were mounted in a stereotaxic apparatus and burr holes drilled in the skull. Microdialysis cannulas were placed bilaterally into the medial prefrontal cortex at an angle of $12^{\circ}$ (coordinates from bregma: A $+3.0 \mathrm{~mm}, \mathrm{~L}+1.8 \mathrm{~mm}, \mathrm{~V}-5.5 \mathrm{~mm})$ and secured with dental cement and two cranial screws (Feenstra et al. 1998). After recovery from the anesthesia, rats were placed in individual Perspex cages $(25 \times 25 \times 32 \mathrm{~cm})$ with free access to food and water.

\section{Behavioral Procedures}

All behavioral procedures were as similar as possible to those of Experiment 1 . Rats were handled and weighed daily during the recovery period. Six d after surgery, the experiment began with the $2 \mathrm{~d}$ of pretraining. The purpose of the pretraining was to familiarize the rat with the reinforcement and the experimental box as described in the first experiment and with the room where dialysis experiments were to be conducted. On the first day of the pretraining session, the rats were transferred to the experimental room, given free access to the chocolate-flavored rice breakfast cereal for $20 \mathrm{~min}$ in a neutral cage, and then placed in the dialysis chamber for $1 \mathrm{~h}$. The cannula inlet was connected to the perfusion pump, without delivering solution. The second day, rats were again allowed to consume reinforcement, placed in the experimental box without the sponges for $10 \mathrm{~min}$, and placed again in the dialysis chamber for $1 \mathrm{~h}$. On the training day, measurements were initiated by an automated injection of dialysate every $16 \mathrm{~min}$; rats were left undisturbed in the dialysis chamber for $2 \mathrm{~h}$ in order to obtain stable baseline measurements. The three last measurements were taken as the baseline. The rats were disconnected, brought back to the experimental room, and placed in the experimental box for training. Given the configuration of the training environment, it was impossible to connect the rat to the dialysis apparatus during the training. Immediately after the last trial, rats were reconnected to the dialysis set-up. Unpaired controls $(n=5)$ were exposed to the reward immediately before the trial and then explored the apparatus containing the three odorous sponges, for the same amount of time as a yoked trained rat (c.f. Tronel and Sara 2002; $\mathrm{n}=5$ ). The pretraining was the same as for the trained group. Thus unpaired rats received equal exposure to all of the elements of the training with the reinforcement preceding the discriminative stimuli. Six $d$ after the training session, trained rats were tested for retention using the same procedure as during training, except that the first trial was not reinforced and there were a total of three trials.

\section{Dialysis Apparatus and Procedure}

For both groups, cannulas were connected to a Harvard 22 perfusion pump delivering Ringer solution $(145 \mathrm{mM} \mathrm{NaCl}, 2.7 \mathrm{mM}$ $\mathrm{KCl}, 1.2 \mathrm{mM} \mathrm{CaCl} 2,1.0 \mathrm{mM} \mathrm{MgCl}_{2}$ ) at a rate of $3 \mu \mathrm{L} / \mathrm{min}$. The dialysate was introduced online into the high-performance liquid chromatography (HPLC) injection loop and automatically injected every 16-17 min. Chromatographic conditions were as described (Feenstra et al. 1998). After the experiment, rats were sacrificed by $\mathrm{CO}_{2}$ inhalation, and their brains were removed, frozen, and cut to verify the placement of the cannulas. All rats had correctly placed cannula in the ventral medial prefrontal cortex.

\section{Data Analysis}

\section{Behavior}

Latency to nose-poke and number of errors were taken as the performance measures. Acquisition and retention scores, in terms of latencies and number of errors, were submitted to an ANOVA with repeated measures (trials). ANOVA was complemented by planned comparisons using Fischer's LSD test.

\section{Microdialysis}

After 120 min of habituation to the dialysis environment during the pretraining period, the measures of NE efflux were stable. Therefore, the mean of the last three values of the 2-h baseline session was calculated for each rat, and the NA values during the posttraining period were expressed as a percentage of this individual baseline value. These normalized scores were submitted to a $2 \times 8$ ANOVA with repeated measures (groups $\times$ time of measurement). Because the initial posttraining value, the measurement of NA efflux for the first $16 \mathrm{~min}$ after transfer and placement in the dialysis environment, was excessively variable among rats (probably due to the manipulation required by connection to the dialysis system), the first sample was not included in statistical analysis. ANOVA results were complemented by planned comparisons using the Fischer's LSD procedure.

\section{ACKNOWLEDGMENTS}

Supported by a bilateral grant from INSERM (France) and NWO (Netherlands) to S.J.S. and M.G.P.F. and from CNRS UMR 7102.

The publication costs of this article were defrayed in part by payment of page charges. This article must therefore be hereby marked "advertisement" in accordance with 18 USC section 1734 solely to indicate this fact.

\section{REFERENCES}

Arnsten, A.F. 1997. Catecholamine regulation of the prefrontal cortex. J. Psychopharmacol. 11: 151-162.

Birrell, J.M. and Brown, V.J. 2000. Medial frontal cortex mediates perceptual attentional set shifting in the rat. J. Neurosci. 20: 4320 4324 .

Bouret, S. and Sara, S.J. 2004. Reward expectation orientation of attention and locus coeruleus-medial frontal cortex interplay during learning. Eur. J. Neurosci. (in press).

Bourtchuladze, R., Frenguelli, B., Blendy, J., Cioffi, D., Schutz, G., and Silva, A.J. 1994. Deficient long-term memory in mice with a targeted mutation of the cAMP-responsive element-binding protein. Cell 79: $59-68$.

De Bruin, J.P., Feenstra, M.G., Broersen, L.M., Van Leeuwen, M., Arens, C., De Vries, S., and Joosten, R.N. 2000. Role of the prefrontal cortex of the rat in learning and decision making: Effects of transient inactivation. Prog. Brain Res. 126: 103-113.

Feenstra, M.G., Botterblom, M.H., and van Uum, J.F. 1998. Local activation of metabotropic glutamate receptors inhibits the handling-induced increased release of dopamine in the nucleus accumbens but not that of dopamine or noradrenaline in the prefrontal cortex: Comparison with inhibition of ionotropic receptors. J. Neurochem. 70: 1104-1113. 
Tronel et al.

Fuster, J.M. 2003. Cortex and mind. Oxford University Press, Oxford. Huang, Y.Y. and Kandel, E.R. 1996. Modulation of both the early and the late phase of mossy fiber LTP by the activation of $\beta$-adrenergic receptors. Neuron 16: 611-617.

Jodo, E., Suzuki, Y., and Kayama, Y. 2000. Selective responsiveness of medial prefrontal cortex neurons to the meaningful stimulus with a low probability of occurrence in rats. Brain Res. 856: 68-74.

Kawaguchi, Y. and Shindou, T. 1998. Noradrenergic excitation and inhibition of GABAergic cell types in rat frontal cortex. J. Neurosci. 18: 6963-6976.

Kesner, R.P. 1989. Retrospective and prospective coding of information: Role of the medial prefrontal cortex. Exp. Brain Res. 74: 163-167.

Kublik, E. and Sara, S.J. 2002. Activity in medial frontal cortex during odour discrimination learning in the rat: Neuronal response to experimental cortex. FENS Abstract 1, A040.14.

Mantz, J., Thierry, A.M., and Glowinski, J. 1989. Effect of noxious tail pinch on the discharge rate of mesocortical and mesolimbic dopamine neurons: Selective activation of the mesocortical system. Brain Res. 476: 377-381.

Milad, M.R. and Quirk, G.J. 2002. Neurons in medial prefrontal cortex signal memory for fear extinction. Nature 420: 70-74.

Morrison, J.H., Grzanna, R., Molliver, M.E., and Coyle, J.T. 1978. The distribution and orientation of noradrenergic fibers in neocortex of the rat: An immunofluorescence study. J. Comp. Neurol. 181: 17-39.

Mulder, A.B., Nordquist, R., Orgut, O., and Pennartz, C.M. 2000. Plasticity of neuronal firing in deep layers of the medial prefrontal cortex in rats engaged in operant conditioning. Prog. Brain Res. 126: $287-301$.

Paxinos, G. and Watson, C. 1986. The rat brain in stereotaxic coordinates. Academic Press, New York.

Quirk, G.J., Russo, G.K., Barron, J.L., and Lebron, K. 2000. The role of ventromedial prefrontal cortex in the recovery of extinguished fear. J. Neurosci. 20: 6225-6231.

Roullet, P. and Sara, S. 1998. Consolidation of memory after its reactivation: Involvement of $\beta$-noradrenergic receptors in the late phase. Neural Plast. 6: 63-68.

Sakaguchi, T. and Nakamura, S. 1987. The mode of projections of single locus coeruleus neurons to the cerebral cortex in rats. Neuroscience 20: $221-230$.

Sara, S.J., Roullet, P., and Przybyslawski, J. 1999. Consolidation of memory for odor-reward association: $\beta$-adrenergic receptor involvement in the late phase. Learn. Mem. 6: 88-96.

Schulz, S., Siemer, H., Krug, M., and Hollt, V. 1999. Direct evidence for biphasic cAMP responsive element-binding protein phosphorylation during long-term potentiation in the rat dentate gyrus in vivo. J. Neurosci. 19: 5683-5692.

Seidenbecher, T., Reymann, K.G., and Balschun, D. 1997. A post-tetanic time window for the reinforcement of long-term potentiation by appetitive and aversive stimuli. Proc. Natl. Acad. Sci. 94: 1494-1499.

Stanciu, M., Radulovic, J., and Spiess, J. 2001. Phosphorylated cAMP response element binding protein in the mouse brain after fear conditioning: Relationship to Fos production. Brain Res. Mol. Brain Res. 94: 15-24.

Tronel, S. and Sara, S.J. 2002. Mapping of olfactory memory circuits: Region-specific c-fos activation after odor-reward associative learning or after its retrieval. Learn. Mem. 9: 105-111.

2003. Blockade of NMDA receptors in prelimbic cortex induces an enduring amnesia for odor-reward associative learning. J. Neurosci. 23: 5472-5476.

Tronel, S., Moricard, Y., and Sara, S.J. 2003. Noradrenergic action in prefrontal cortex in the late stage of memory formation. Acta Neurobiol. Exp. 63: Supplement L54.

Yin, J.C. and Tully, T. 1996. CREB and the formation of long-term memory. Curr. Opin. Neurobiol. 6: 264-268.

Received January 22, 2004; accepted in revised form May 6, 2004. 


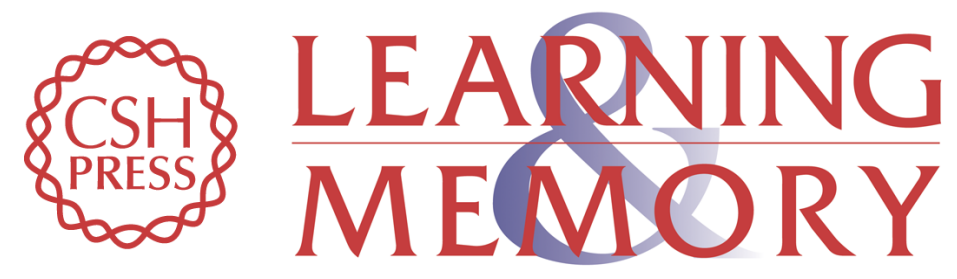

\section{Noradrenergic Action in Prefrontal Cortex in the Late Stage of Memory Consolidation}

Sophie Tronel, Matthijs G.P. Feenstra and Susan J. Sara

Learn. Mem. 2004, 11:

Access the most recent version at doi:10.1101//m.74504
Related Content Learning in a Simple Motor System
Dianne M. Broussard and Charles D. Kassardjian
Learn. Mem. March , 2004 11:127-136
References This article cites 23 articles, 8 of which can be accessed free at: http://learnmem.cshlp.org/content/11/4/453.full.html\#ref-list-1
Articles cited in:
http://learnmem.cshlp.org/content/11/4/453.full.html\#related-urls
License Email Alerting
Service

